\title{
ANALISIS KORELASI ANTARA POROSITAS DAN FASIES BATUAN KARBONAT (STUDI KASUS DI FORMASI WONOSARI DAN KUBAH BAYAH)
}

\author{
Subhan Arif ${ }^{1}$, Nur Widi Astanto Agus Tri Heriyadi ${ }^{2}$, Muhamad Rio Dwi Patra ${ }^{3}$, Nanda \\ Budrianto ${ }^{4}$ \\ 1,2,3,4 Jurusan Teknik Geologi, Institut Sains \& Teknologi AKPRIND Yogyakarta \\ Email: ${ }^{1}$ s.arif@akprind.ac.id, ${ }^{2}$ nurwidi@akprind.ac.id, ${ }^{3}$ muhamadrio20@gmail.com, \\ ${ }^{4}$ nandabudrianto@gmail.com
}

Masuk: 15 Januari 2021, Revisi masuk: 23 Januari 2021, Diterima: 3 Agustus 2021

\begin{abstract}
Carbonate rock is one of rocks that has the potential to become a reservoir rock for petroleum. Unfortunately carbonate rock has a high uncertainty for its porosity value. Porosity is an important aspect of reservoir rock. The aim of this study was to create a correlation model between rock facies and the quality of porosity. The methodology used in this study was taking samples and then it was analyzed using rock sampling to analyze thin sections and rock slabs in the laboratory. The results of the research showed that limestone samples were divided into 2 SMF groups (SMF 8 and SMF 18). They were in the facies zone in the interior platform. The porosity value showed $0.05 \%-9.4 \%$ (negligible - poor). It can be concluded that there was a weak correlation between SMF and the quality of the limestone porosity, although there were still anomalies as occurred in sample $\mathrm{Y} 3$ due to the moldic porosity which increased the number of pores in the sample
\end{abstract}

Keywords: Facies, Limestone, Porosity.

\section{INTISARI}

Batuan karbonat merupakan salah satu batuan yang berpotensi menjadi batuan reservoir minyak bumi. Sayangnya batuan karbonat atau memiliki tingkat ketidakpastian yang tinggi untuk nilai porositasnya. Porositas merupakan aspek penting dari batuan reservoir. Tujuan dari penelitian ini adalah membuat model korelasi antara fasies batuan dengan kualitas porositas. Metodologi yang digunakan dalam penelitian ini adalah pengambilan sampel batuan untuk menganalisis bagian tipis dan lempengan batuan di laboratorium. Hasil penelitian adalah sampel batu gamping dibagi menjadi 2 kelompok SMF (SMF 8 dan SMF 18) berada pada zona fasies yaitu pada anjungan interior. Nilai porositas menunjukkan 0,05\% - 9,4\% (diabaikanburuk). Kesimpulannya adalah terdapat korelasi yang lemah antara SMF dengan kualitas porositas batugamping, walaupun masih terdapat anomali seperti yang terjadi pada sampel Y3 akibat porositas moldic yang meningkatkan jumlah pori dalam sampel.

Kata-kata kunci: Batugamping, Fasies, Porositas.

\section{PENDAHULUAN}

Sumber energi fosil masih mendominasi kebutuhan energi di seluruh dunia. Batuan karbonat merupakan salah satu batuan yang memiliki potensi menjadi reservoir minyak bumi di seluruh dunia. Sayangnya batuan karbonat atau dalam hal ini adalah batugamping memiliki tingkat ketidakpastian yang tinggi untuk nilai porositasnya. Porositas adalah salah satu aspek penting pada batuan reservoir. Nilai porositas akan menentukan seberapa baik batuan tersebut menyimpan minyak dan gas bumi.

Penelitian mengenai batu gamping di seluruh dunia telah banyak dilakukan namun masih belum dapat menghasilkan suatu model pasti dari nilai porositas batugamping. Sebagian menilai porositas batugamping dari diagnosisnya dan rekahan yang terjadi akibat proses sekunder Brady dan Thyne (2016), Panza, dkk. (2019).

Beberapa batu gamping yang memiliki penyebaran cukup luas adalah di selatan Jawa Tengah yaitu Formasi Wonosari. Batugamping Formasi Wonosari berumur Miosen (Mukti, 2005). Selain itu, batugamping yang juga memiliki umur relatif sama di bagian selatan Pulau Jawa bagian barat adalah batugamping Formasi Cijengkol dan Citarate di daerah Bayah. Batu gamping ini memiliki umur relatif Oligosen sampai Miosen dari hasil analisis biostratigrafi (Arif, 2019).

Penelitian ini dilakukan pada dua daerah tersebut untuk membuat suatu model analogi hubungan antara nilai porositas 
batugamping dengan fasies batuan batugamping. Selain itu kedua daerah tersebut memiliki umur yang sama, sehingga diasumsikan memiliki tingkat diagenesis yang tidak jauh berbeda.

Tujuan dari penelitian ini adalah untuk membuat suatu model korelasi antara fasies batuan batugamping dengan nilai porositasnya.

\section{METODE PENELITIAN}

Penelitian ini menggunakan metode analisis kualitatif dan kuantitatif. Metode kualitatif yang dilakukan adalah identifikasi jenis batuan sampai fasies batuan batugamping. Analisis kualitatif dilakukan menggunakan gabungan analisis petrografi dan porositas batuan. Rancangan penelitian ini dapat dilihat pada Gambar 1.

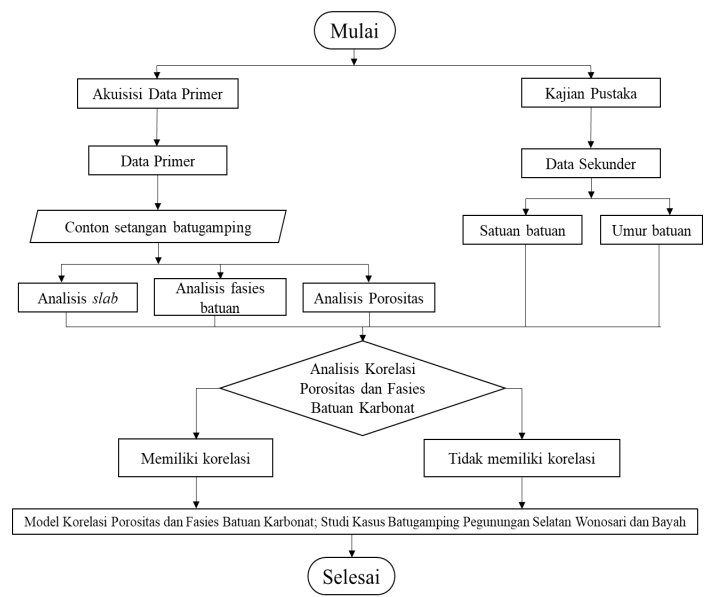

Gambar 1. Diagram rancangan penelitian

\section{PEMBAHASAN \\ Lokasi Penelitian dan Pengambilan Sampel}

Pengumpulan data yang dilakukan pada penelitian ini dilakukan menggunakan metode pengambilan contoh batuan untuk dilakukan analisis sayatan tipis di laboratorium. Pengambilan sampel dilakukan pada dua lokasi penelitian, yaitu pada Pegunungan Selatan Jawa Tengah dan Dome Bayah. Terdapat lima sampel yang berasal dari Pegunungan Selatan Jawa Tengah adalah batugamping dari formasi wonosari, dan yang berasal dari Kubah Bayah adalah Formasi Citarate (Gambar 2).

\section{Analisis Litofasies}

Jumlah sampel yang dianalisis sebanyak delapan sampel. Tiga sampel berasal dari
E-ISSN: 2714-8025

Kubah Bayah dan lima sampel dari pegunungan selatan formasi Wonosari. Deskripsi litofasies mengacu pada klasifikasi batugamping yang disusun oleh Dunham (1962) dan mikrofasies menggunakan Standar Mikrofasies (SMF) yang dikemukakan oleh Flugel (2010). Lokasi pengambilan sampel dapat dilihat pada Gambar 2.

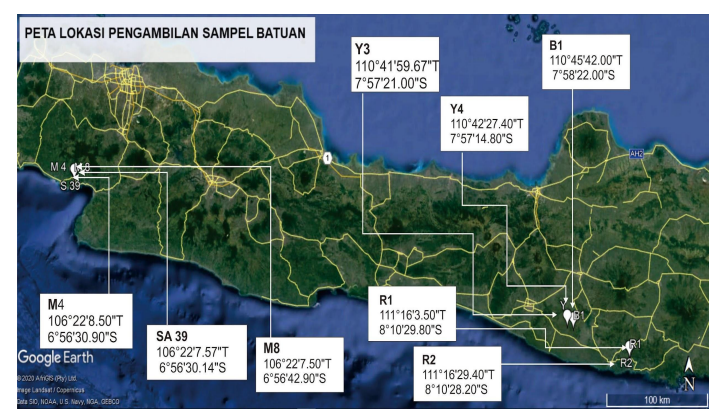

Gambar 2. Lokasi pengambilan sampel

Ketiga sampel dari Bayah Dome tersebut memiliki karakter yang sama. Sampel M4 dan M8 menunjukkan tekstur grainstone (Gambar 3 dan 4). Hanya sampel SA 39 yang menunjukkan tekstur packstone (Gambar 5).

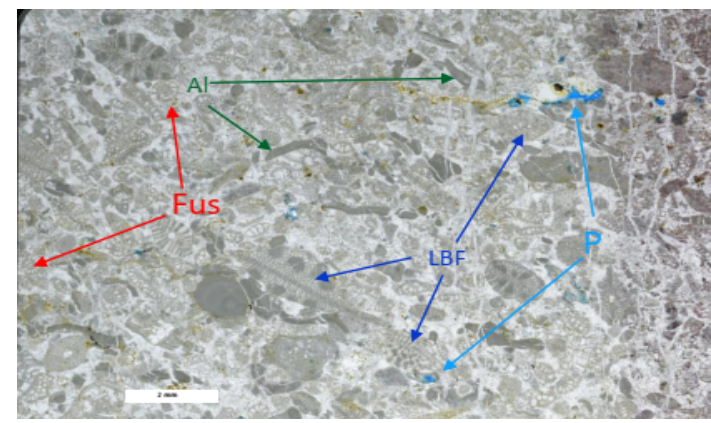

Gambar 3. Sampel M4 (Al: Red Algae, Fus: Fussilinid Bentonic Foraminifera, LBF: Large Bentonic Foraminifera, P: Vuggy Porrosity)

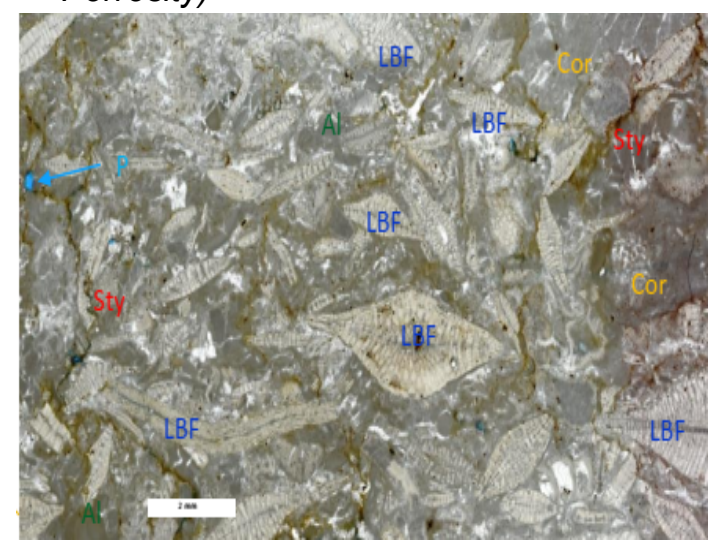


Gambar 4. Sampel M8 (LBF: Large Bentonic Foraminifera, Cor: Coral Coast, Sty: Stylolites, P: Vuggy Porosity)

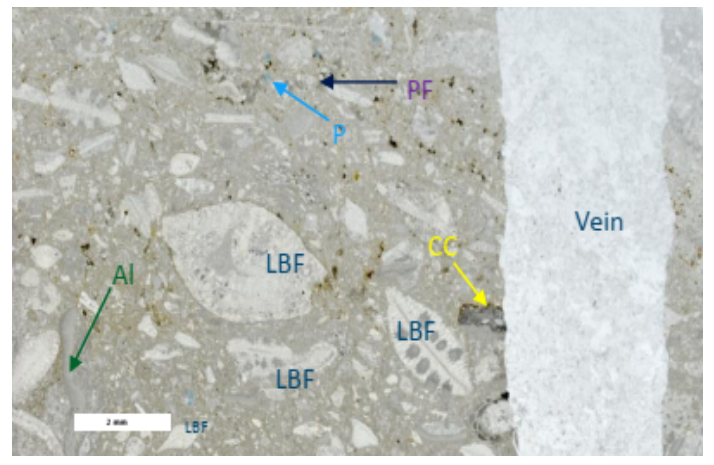

Gambar 5. Sampel SA 39, (Al: Red Algae, PF: Planktonic Foraminifera, LBF: Large Bentonic Foraminifera, $P$ : Vuggy Porosity, CC: Clay Clast)

Berdasarkan uraian tersebut, sampel M4 adalah Bentonic Foraminifera Grainstone. Sampel M8 adalah Large Bentonic Foraminifera Grainstone dan Sampel SA 39 adalah Large Bentonic Foraminifera Packstone. Mengacu pada Mikrofasies Standar karya Flugel 2010, ketiganya adalah SMF 18. Mikrofasies tersebut terindikasi mendukung lingkungan pengendapan terumbu karang. Berbeda dengan sampel dari Bayah Dome, sampel dari formasi Wonosari terbagi menjadi dua karakter yang berbeda berdasarkan mikrofasiesnya. Sampel R1 dan R2 memiliki tekstur packstone (Gambar 6 dan 7).

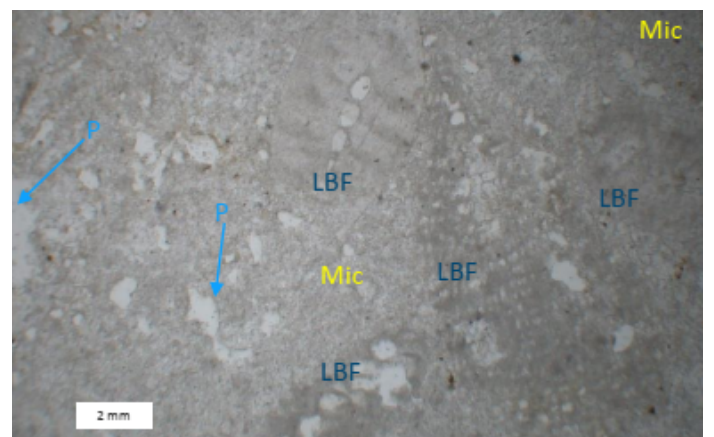

Gambar 6. Sampel R1 (LBF: Large Bentonic Foraminifera, P: Vuggy Porrosity, Mic: Micrite)

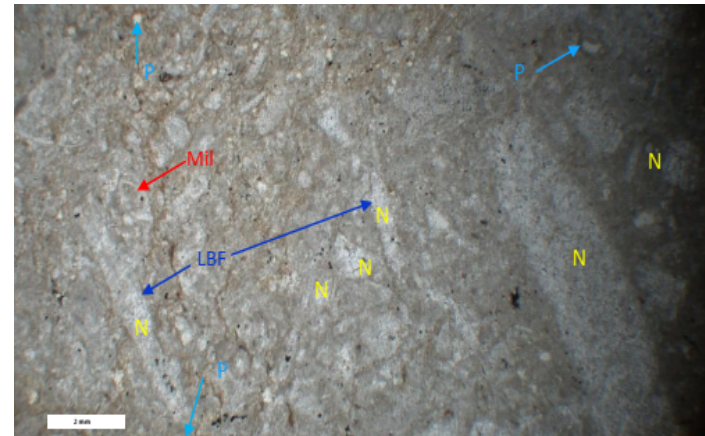

Gambar 7. Sampel R2, (LBF: Large Bentonic Foraminifera, $P$ : Vuggy Porrosity, N: Neomorfisme, Mil: Milliolids)

Sampel B1 dan Y4 menunjukkan tekstur wackestone dengan lumpur yang lebih dominan sebagai massa tanah (mud support) (Gambar 8 dan 9). Hanya sampel Y3 yang menunjukkan tekstur grainstone (Gambar 10).

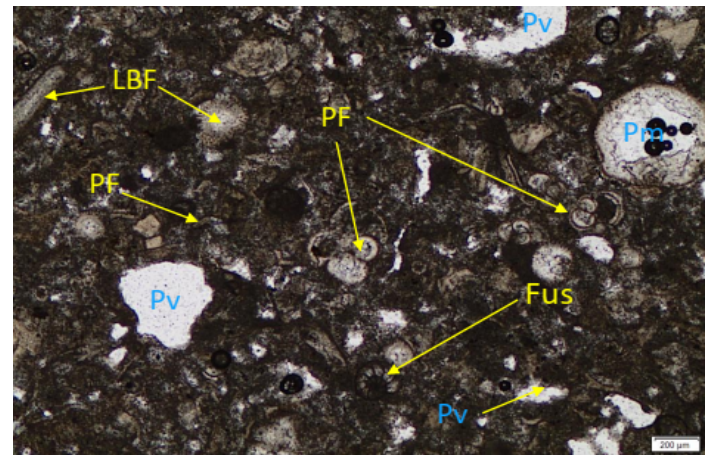

Gambar 8. Sampel B1, (LBF: Large Bentonic Foraminifera, Pv: Vuggy Porrosity, Pm: Moldic Porosity, PF: Planktonic Foraminifera, Fus: Fusulinid)

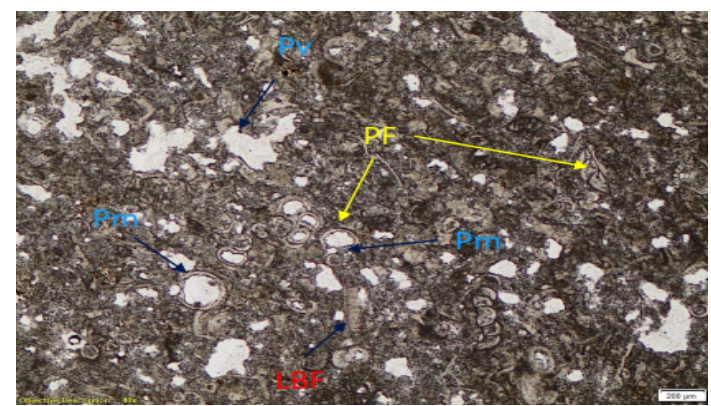

Gambar 9. Sampel Y4 (Pv: Vuggy Porrosity, Pm: Moldic Porosity, PF: Planktonic Foraminifera) 


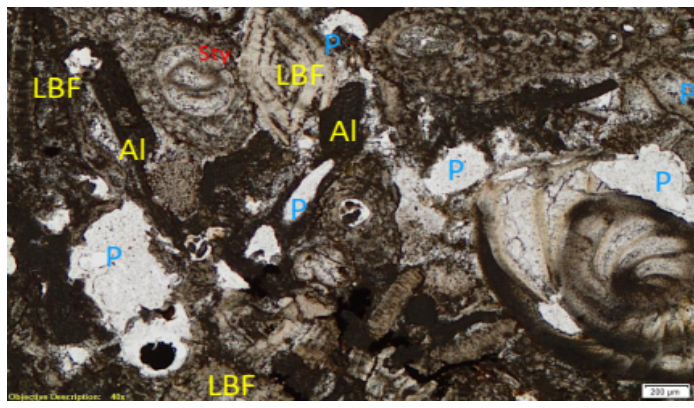

Gambar 10. Sampel Y3 (LBF: Large Bentonic Foraminifera P: Vuggy Porrosity, Al: Red Algae)

Berdasarkan uraian ini, sampel R1 adalah Large Bentic Formainifera Packstone (SMF 18). Sampel R2 adalah Bentonic Foraminifera Packstone (SMF 18) dan Sampel $Y \quad 3$ adalah Large Bentonic Foraminifera Grainstone (SMF 18). Sampel nomor B1 dan Y4 keduanya adalah Whole Fossil Wackestone (SMF 8). Mikrofasies tersebut diindikasikan untuk mendukung lingkungan pengendapan terumbu.

\section{Analisis Porositas}

Analisis porositas dilakukan pada semua sampel. Metode yang digunakan adalah perbandingan persentase antara luas pori total dan luas penampang tipis yang ditunjukkan di bawah mikroskop. Perhitungan luas pori menggunakan software ImageJ. Rangkuman perhitungan porositas dapat dilihat pada Tabel 1.

Jenis pori yang diamati pada semua sampel berjamur dan vuggy. Pori mouldic menggambarkan proses pelarutan selektif yang luar biasa dari butiran.

Tabel 1. Rangkuman dari analisis porositas

\begin{tabular}{|c|c|c|}
\hline $\begin{array}{c}\text { Sample } \\
\text { ID }\end{array}$ & \% Porosity & $\begin{array}{c}\text { Quality for Reservoir } \\
\text { Rock }\end{array}$ \\
\hline M4 & 0.334 & Negligible \\
M8 & 0.081 & Negligible \\
SA 39 & 0.05 & Negligible \\
R1 & 2.521 & Negligible \\
R2 & 0.189 & Negligible \\
Y3 & 8.2 & Poor \\
B1 & 6.457 & Poor \\
Y4 & 9.469 & Poor \\
\hline
\end{tabular}

Pori-pori vuggy mewakili pori kain non-selektif dan pelarutan batuan yang lebih intens. Jenis vuggy lebih sering ditemukan pada batuan dengan fasies berbutir lebih kasar. Dalam penelitian ini batuan dengan allochem foraminifera bentonik besar.
Sedangkan pori-pori tipe mouldic ditemukan pada batuan dengan foraminifera planktonik sebagai allochem.

Batugamping merupakan salah satu batuan yang memiliki ketidakpastian yang sangat tinggi. Penelitian ini mencoba meminimalkan ketidakpastian tersebut dengan mencari pola hubungan antara fasies batugamping dengan kualitas porositasnya.

Delapan sampel yang dianalisis dibagi menjadi dua kelompok fasies (SMF 18 dan SMF 8). Porositas batugamping juga dibagi menjadi dua kelompok (negligible dan poor). Untuk melihat pola porositas dan sebaran SMF pada sampel batu gamping dapat dilihat pada Gambar 11.

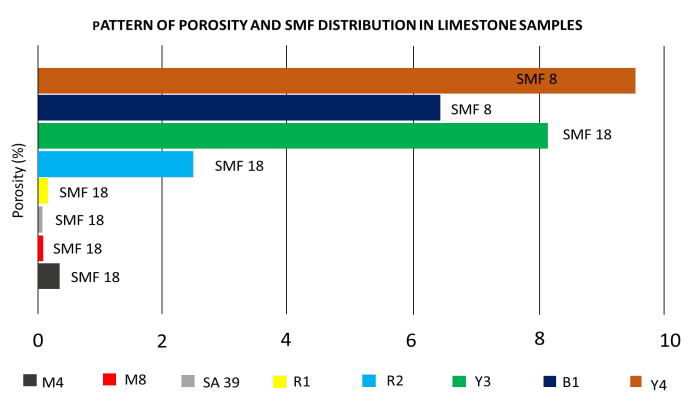

Gambar 11. Diagram yang menunjukkan pola porositas dan sebaran SMF pada sampel batugamping

Dapat dilihat pada diagram di Gambar 11, beberapa SMF 18 menunjukkan pola yang sama, porositas sangat kecil (dapat diabaikan). Namun sampel $Y 3$ yang tidak menunjukkan pola yang sama yaitu $\mathrm{Y} 3$ (SMF 18). Sampel ini menunjukkan nilai porositas yang lebih baik dibandingkan dengan SMF 18 lainnya. Sampel dengan fasies SMF 8 menunjukkan kualitas porositas yang buruk.

Hal ini menggambarkan lemahnya korelasi antara kualitas porositas dan fasies batugamping. Untuk itu perlu dilakukan penambahan jumlah sampel dan penelitian dengan parameter lain yang mungkin berperan dalam mempengaruhi porositas batuan seperti diagenesis.

\section{KESIMPULAN}

Berdasarkan hasil analisis yang telah dilakukan terhadap delapan sampel dari dua lokasi yang berbeda, terdapat dua jenis fasies batuan yang berhasil diidentifikasi yaitu SMF 8 dan SMF 18. Keduanya berada pada lingkungan back reef. 
Hasil analisis porositas yang didapatkan dari kedelapan sampel tersebut menunjukan kualitas yang buruk sampai dapat diabaikan sebagai reservoir minyak bumi. Seluruh SMF 8 dari sampel yang dianalisis menunjukan kualitas yang buruk. Sedangkan sebagian besar SMF 18 menunjukan kulaitas porositas yang dapat diabaikan kecuali satu sampel yang menunjukan kualitas yang buruk (relativ lebih baik). Hal ini memberikan gambaran sekilas bahwa fasies dan porositas memiliki korelasi. Karena jumlah sampel yang masih kurang jumlahnya untuk dianggap valid (mewakili seluruh SMF) maka korelasi tersebut masih tampak lemah.

\section{DAFTAR PUSTAKA}

Arif, S., 2019, Rekonstruksi Model Pengendapan Batugamping Berumur Oligo-Miosen Daerah Kubah Bayah dan Sekitarnya, Kabupaten Lebak, Provinsi Banten, Provinsi Jawa Barat, Tesis, Institut Teknologi Bandung.

Brady, P.V. dan Thyne, G., 2016, Functional Wettability in Carbonate Reservoirs, Energy \& Fuels, 30 (11): 9217-9225.

Dunham, R.J., 1962, Classification of Carbonate Rocks According to Depositional Texture dalam Ham, W.E. ed., Classification of Carbonate Rocks, American Association of Petroleum Geologists, Tulsa, Oklahoma, 108-121.

Flugel, E., 2010, Microfacies of Carbonate Rocks, Analysis, Interpretation and Application, 2nd edition, Springer.

Mukti, M.M.R., 2005, Carbonate Depositional Environment and Platform Morphology of The Wonosari Formation In The Area East of Pacitan, RISET Geologi dan Pertambangan, 15(2): 29-38.

Panza, E., Agosta, F., Rustichelli, A., Vinciguerra, S.C., Ougier-Simonin, A.,
Dobbs, M., dan Prosser, G., 2019, Meso-to-microscale Fracture Porosity In Tight Limestones, Results of An Integrated Field and Laboratory Study, Marine and Petroleum Geology, 103: 581-595.

\section{BIODATA PENULIS}

Subhan Arif, S.T., M.T., lahir di Samarinda pada tanggal 22 April 1991, menyelesaikan pendidikan S1 Jurusan Teknik Geologi pada Institut Sains \& Teknologi AKPRIND Yogyakarta tahun 2014 dan S2 Jurusan Teknik Geologi pada Institut Teknologi Bandung tahun 2019. Saat ini tercatat sebagai Dosen Tetap pada Jurusan Teknik Geologi dengan jabatan akademik Asisten Ahli pada bidang minat sedimentologi dan geologi minyak bumi.

Nur Widi Astanto Agus Tri Heriyadi, S.T., M.T., lahir di Sleman pada tanggal 21 Agustus 1979, menyelesaikan pendidikan S1 Jurusan Teknik Geologi pada Universitas Pembangunan Nasional Veteran Yogyakarta tahun 2003 dan S2 Jurusan Teknik Geologi pada Universitas Pembangunan Nasional Veteran Yogyakarta tahun 2012. Saat ini tercatat sebagai Dosen Tetap pada Jurusan Teknik Geologi dengan jabatan akademik Asisten Ahli pada bidang minat geologi batubara dan geokomputasi.

Muhamad Rio Dwi Patra, lahir di Cirebon pada tanggal 26 Mei 1998 saat ini tercatat sebagai mahasiswa Program Studi Teknik Geologi Institut Sains \& Teknologi AKPRIND Yogyakarta.

Nanda Budrianto, lahir di Duri pada tanggal 9 November 1997 saat ini tercatat sebagai mahasiswa pada Program Studi Teknik Geologi Institut Sains \& Teknologi AKPRIND Yogyakarta. 